\title{
Examining the Relationship between Organizational Cynicism and Organizational Change: A Study from Egyptian Context
}

\author{
Wageeh A. Nafei ${ }^{1}$ \\ ${ }^{1}$ University of Sadat City, Menoufia, Egypt \\ Correspondence: Wageeh A. Nafei, University of Sadat City, Menoufia, Egypt. E-mail: dr.wageeh1965@yahoo.com
}

Received: June 7, 2013

Accepted: June 16, 2013

Online Published: June 20, 2013

doi:10.5430/jbar.v2n2p1

URL: http://dx.doi.org/10.5430/jbar.v2n2p1

\begin{abstract}
Organizational cynicism and change are two intertwined phenomena which constitute an important subject matter in organizational behavior literature. One of the main causes of organizational cynicism is organizational change.

Drawing on the literature review, there are some studies regarding organizational cynicism and organizational change. In Egypt, limited research has been conducted, but the present study attempts to find out whether there is a relationship between organizational cynicism and change.

This study was conducted at Teaching Hospitals in Egypt. It is the first empirical work ever done so far in the field of organizational cynicism and its relation with organizational change.

The evaluative attitudes of the employees towards organizational cynicism and change are investigate. The relationship between organizational cynicism and change will be illustrated. Three groups of employees were examined. Three hundred and fifty seven questionnaires were distributed and 300 usable questionnaires were returned, a response rate of $84 \%$.

The results reveal that there are differences among the three groups of employees regarding their evaluative attitudes towards organizational cynicism and change. Besides, the attitudes toward organizational cynicism and change are related. Hence, recommendations include the necessity to pay more attention to organizational cynicism as a common phenomenon in organizations. Finally, the implications of this study are discussed.
\end{abstract}

Keywords: Organizational cynicism, Organizational change

\section{Introduction}

Organizational cynicism is an outcome of an employees' belief that organizations lack honesty. More specifically, expectations of morality, justice, and honesty are violated. Over the years, researchers have become more interested on issues relating to organizational cynicism. The concept of cynicism has become the subject of various disciplines in social sciences like philosophy, religion, political science, sociology, management and psychology (Ince \& Turan, 2011).

Organizational cynicism and change are two intertwined phenomena which constitute an important subject matter in organizational behavior literature. Organizational change is considered one of the main causes of organizational cynicism. It becomes imperative for managers to take into consideration the impact of organizational change on employees because "the people in an organization are crucial to its performance and the quality of work life within it" (Rainey, 2003).

There was a significant relationship between the number of complaints with cynicism related to organizational change and reduction of organizational commitment (Wanous et al., 2000). The researchers were able to identify three types of organizational cynicism. They are cynicism about change, cynicism about the management and general cynicism (Stanley et al., 2005).

Rubin et al., (2009) believe that organizational cynicism is associated with the reduction of its intention to create organizational change, organizational commitment, job satisfaction and organizational citizenship behavior.

Organizational cynicism is an attitude brought about by ill-managed change efforts. It is characterized with pessimism and distrust about the future success of organizational change efforts and ability of the actors trying to perform changes that may be incompetent and/or lazy (Ince \& Turan, 2011). 
There are three important factors needed for any organizational change to be successful.

- First, it becomes imperative for managers to communicate upcoming organizational changes before, during, and after each change. "When leaders unequivocally communicate standards, they honor everyone's desire to their very best. They elevate the human spirit" (Kouzes \& Posner, 2003). This strategy will help employees better prepare for any upcoming changes.

- Second, it is important for managers to hire employees with high levels of positive intelligence. According to Achor (2012), "Research shows that when people work with a positive mindset, performance on nearly every level-productivity, creativity, engagement-improves". Research has shown that if an employee is happy, he or she will perform at higher levels and as a result will be more inclined to get a promotion. In fact, in a sweeping meta-analysis of 225 academic studies, researchers found that "happy employees are, on average, $31 \%$ more productive. Employees with high levels of positive intelligence are more likely to embrace organizational changes".

- Third, managers should also consider using a transformational leadership style when dealing with organizational change and employee cynicism. Transformational leadership can be defined as a "dynamic leadership behavior that inspires and also transforms the way followers think" (Kaifi, 2013). A transformational leadership style can be effective because the manager will be able to transform the way cynical employees view organizational change. The transformational leader will be able to show the benefits of changes and how it will assist the organization with goal accomplishment.

It should be mentioned that studies regarding cynicism in Egypt are novel and in its rudimentary stages. Consequently, theoretical and empirical studies on this important topic are needed to better understand the short-term and long-term implications on organizations. For the purpose of this study, cynicism is defined as an employee having negative feelings such as anger, disappointment, and hopelessness. Ultimately, numerous problems emerge for both staff and organizations (Özler et al., 2010).

The importance of organizational cynicism in the Arab environments has not received its due share of interest. The relationship between organizational cynicism and change has not been thoroughly investigated. Therefore, the current study is trying to examine the attitudes of employees toward organizational cynicism at Teaching Hospitals in Egypt and its relation with organizational change.

The subject of organizational cynicism is a modern subject of interest to a large number of researchers in the non-Arab environments in general, but it is still in its infancy in the Arab environment. Therefore, the current study is trying to shed light on the concept, dimensions and ways of measuring organizational cynicism and change at Teaching Hospitals in Egypt.

The current study is trying to examine the attitudes of employees toward organizational cynicism (the cognitive dimension, the affective dimension, and the behavioral dimension) and change. This elucidates the relationship between organizational cynicism and change, particularly in the Egyptian context.

Despite the progress in the theoretical aspect of organizational cynicism, there is still a need for further study and investigation and analysis to enrich the theoretical and applied research.

In the Arab environment, organizational cynicism is still in its infancy, and there are not enough theoretical writings on the subject. It has not received its share of attention in application. This reveals the importance of the present study theoretically and practically for determining the dimensions of organizational cynicism and ways of measuring organizational cynicism and change. This is in addition to the importance of the pivotal role played by organizational cynicism and change at Teaching Hospitals in Egypt.

Some studies have been conducted on the relationship between organizational cynicism and change. However, no study had been conducted in Egypt. This study aims at identifying the extent of similarities or differences among the employees in regard to organizational cynicism and change. Also, it will recognize and describe the type and degree of the relationship between organizational cynicism and change at Teaching Hospitals in Egypt. This will help researchers analyze the relationship between organizational cynicism and change at Teaching Hospitals in Egypt. It will investigate the evaluative attitudes of the employees at Teaching Hospitals in Egypt towards organizational cynicism and change.

The study is structured as follows: Section one is introductory. Section two presents the literature review. Section three presents the research design. Section four explains the research methodology. Empirical results are provided in section five. Section six handles the main conclusions and some recommendations for dealing with organizational cynicism at Teaching Hospitals in Egypt. 


\section{Theoretical Background}

\subsection{Organizational Cynicism}

Cynicism can be described as being negative and pessimistic about others. Employees who are cynical can influence the entire organization and can hinder the organization from reaching its goals. Cynical employees believe that their colleagues are selfish and self-centered (Barefoot et al., 1989).

Some factors that influence cynicism are: dealing with stress, disagreement with organizational expectations, lack of social support and recognition, not having a voice in the decision-making process, unbalanced distribution of power, and lack of communication (Reichers et al., 1997). Cynics believe that employees have low-levels of critical thinking capabilities and are not worthy of trust or loyalty (Abraham, 2000). It should be mentioned that some researchers believe that cynicism is a personality trait or attitude rather than a lifestyle (Özgener et al., 2008).

To sum up, cynicism has become the norm in many organizations in the US and may also be the case in Egypt and other countries around the world. Some may argue that this is a direct result to job satisfaction levels decreasing over the last decade. One survey showed that just $49 \%$ of Americans are satisfied with their jobs, down from $58 \%$ a decade ago (Koretz, 2003).

Andersson (1996) defines organizational cynicism as general or specific attitudes of disappointment, insecurity, hopelessness, anger, mistrust of institutions or persons, group, ideology and social skills. It is a negative attitude toward one's employing organization, comprising three dimensions: (1) a belief that the organization lacks integrity, (2) negative affect toward the organization, and (3) tendencies towards disparaging and critical behaviors toward the organization that are consistent with these beliefs and effects (Dean et al., 1998).

Organizational cynicism is the belief that an organization lacks honesty causing hard-hitting reputation and critical behaviors when it is combined with a strong negative emotional reaction (Abraham, 2000). It is an estimation based on an individual's work experience of the evaluator (Cole et al., 2006). It may refer to being unsatisfied with the organization. It is defined as an attitude formed by faith, feelings and behavioral tendencies. It is a negative attitude including the three dimensions developed by a person to his organization, namely; cognitive, affective, and behavioral structure of the cynical construct. The cognitive dimension of organizational cynicism is the belief that organization lacks honesty and transparency. The affective dimension of organizational cynicism refers to the emotional and sentimental reactions to the organization. The behavioral dimension of organizational cynicism refers to negative tendencies (Dean et al., 1998, Stanley et al., 2005).

\subsection{Organizational Change}

Organizational change is at the forefront of the academic and managerial environment (Pettigrew et al., 2001). It showed a diversity of the organization in its environment, and also the interaction of the technical and human activities that had interrelated dimensions in the organization (Cao et al., 2000).

It is important to mention that many organizations deal with organizational change on a regular basis. A case in point is how Yahoo's CEO (i.e., Marissa Mayer) recently decided to change and ban the telecommuting policy. "Organization are goal-oriented, purposive entities, and their effectiveness is pursuing those goals influences the quality of our lives and even our ability to survive" (Rainey, 2003).

This unexpected change will create many cynics who do not agree with its decision and feel disrespected. A leader should know that, "Respect is not something one can imitate, but something one must embody" (Lawrence-Lightfoot, 2000).

As such, managers should consider consulting with employees during such drastic changes. "Learning to understand and see things from another's perspective is absolutely crucial to building trusting relations and to career success" (Kouzes, 2003).

Some organizational changes are necessary in order for the organization to compete with its competitors. For example, many hospitals made a significant change from using analog x-rays to digital images. Kaifi (2010) explains, "technological advancements have allowed for digital images (x-rays) to be analyzed by medical doctors (radiologists) outside of the U.S. As a result, radiologists in the US have become cynical". Thus, managers are expected to formulate and implement meaningful changes to the organization that complement the organization's culture.

Khademian (2002) explains, "Determining what needs to be changed and articulating those changes is an essential part of the effort to manage the integration of cultural roots. If managers want to change how the job gets done, they must understand the commitments driving the work of the program and how those commitments might need to 
change. Articulating those changes helps participants to see the task, the resources, and the skills they bring to the table, and the environment in which they work, differently". Organizational change can be a stressful time for employees for a number of reasons ranging from learning a new task to jobs being eliminated. As such, some employees are more resistant to change while others are more receptive to change.

There are three types of individuals' or groups' response to organizational change. They are affective, cognitive and instrumental. Affective response refers to the feeling of being linked to satisfaction or anxiety about change. Cognitive responses are opinions relating to usefulness and necessity and about knowledge required to handle change. Instrumental responses refers to actions already taken or which will be taken to handle the change (Elizur \& Guttman, 1976).

Dunham et al. (1989) suggested that there are three types of attitudes toward change; affective, cognitive and behavioral.

- The affective component consists of the feelings a person has toward an attitude object, which involves evaluation and emotion, and is often expressed as like or dislike for the attitude object.

- The cognitive component of an attitude consists of the information a person possesses about a person or thing which is based on what a person believes to be true.

- The behavioral tendency concerns the way a person intends to behave toward an attitude object.

The three types of attitudes are more critical. Organizational changes should start by the cognitive or affective mode and then followed by the behavioral mode. The cognitive mode can be an effective mode to be addressed first. This is because once a person has information and knowledge of the potential changes to be made, his or her feelings toward change may be changed to favor such changes. It should be highlighted that handling the cognitive component on attitude toward change can be a daunting task if it is not well communicated. This will be demonstrated by the behavioral mode of the person in responding to the changes.

\section{Research Questions and Hypotheses}

The research process includes both questions and hypotheses. The research questions of this study are as follows:

Q1: Are there essential variations among the employees (physicians, nurses, and administrative staff) at Teaching Hospitals in Egypt towards organizational cynicism?.

Q2: Are there fundamental differences among the employees (physicians, nurses, and administrative staff) at Teaching Hospitals in Egypt towards organizational change?.

Q3: What is the relationship between organizational cynicism (the cognitive dimension, the affective dimension, the behavioral dimension) and organizational change at Teaching Hospitals in Egypt?

Drawing on these research questions, the research hypotheses of this study are as follows:

H1: There is no significant discrimination among the employees (physicians, nurses, and administrative staff) at Teaching Hospitals in Egypt towards organizational cynicism.

H2: There is no significant differences among the employees (physicians, nurses, and administrative staff) at Teaching Hospitals in Egypt towards organizational change.

H3: There is no relationship between organizational cynicism (the cognitive dimension, the affective dimension, the behavioral dimension) and organizational change at Teaching Hospitals in Egypt.

\section{Research Strategy}

\subsection{Population and Sample}

The study was conducted at Teaching Hospitals in Egypt. This sector includes nine Hospitals. They are Ahmed Maher, El-Matrya, El-Galaa, El-Sahel, Benha, Shebin El-Kom, Damnhour. The researcher excludes Hospitals in Sohag and Aswan. This explains why the population of this study includes 5,135 employees. The random sampling was adopted for collecting the primary data due to difficulty of having access to all of the items of the research population, because of time limitations. The stratified random sample was used while selecting items from the different categories of employees. The sample size was determined from the following formula (Daniel, 1999):

$$
\mathrm{n}=\frac{\mathrm{N} \times(Z)^{2} \times \mathbf{P}(1-\mathrm{P})}{\mathrm{d}^{2}(\mathrm{~N}-1)+(\mathrm{Z})^{2} \times \mathrm{P}(1-\mathrm{P})}
$$


Accordingly, the sample size has become 357 employees (physicians, nurses, and administrative staff) at Teaching Hospitals in Egypt.

Table 1. Distribution of the Sample Size

\begin{tabular}{|l|l|l|l|}
\hline Job Category & $\begin{array}{l}\text { Number of } \\
\text { Population }\end{array}$ & Percentage & Sample Size \\
\hline Physicians & 1926 & $37.50 \%$ & 357 X 37.50\% $=134$ \\
\hline Nurses & 2714 & $52.86 \%$ & 357 X 52.86\%=189 \\
\hline Administrative Staff & 495 & $9.64 \%$ & 357 X $9.64 \%=34$ \\
\hline Total & $\mathbf{5 1 3 5}$ & $\mathbf{1 0 0 \%}$ & $\mathbf{3 5 7}$ X 100\% $=\mathbf{3 5 7}$ \\
\hline
\end{tabular}

\section{Source: Personnel Department at Teaching Hospitals in Egypt, 2013}

Table (1) proves proportionality with the number of employees in the research population. Virtually, random choice of categories was accomplished utilizing the lists of employees at the Staff Affairs Department, Teaching Hospitals in Egypt

\subsection{Procedure}

In order to achieve the objectives of the study, a draft questionnaire was developed based on comprehensive reviews of the extant literature. Only 25 questionnaires were piloted by a closed circle of employees, requiring some modification. Data collection was accomplished through contacting informants in informal interviews. Each informant was given a list of questions and enough time to answer them.

The questionnaire was four pages. Each questionnaire included a covering letter explaining the aim of the study to reassure respondents of the confidentiality of responses and give instructions for completing the questionnaire. It was classified into two parts. Part one includes questions that aim at obtaining details such as organizational cynicism and change. Part two consists of questions seeking information about demographics (such as job title, sex, marital status, age, educational qualifications, and experience). Most questions required the respondents to assign a score rating on five-point Likert scale. Data collection took approximately two months. Survey responses were $84 \%, 300$ completed surveys out of the 357 distributed.

About $36 \%$ of the participants were physicians, $52 \%$ nurses, $11 \%$ administrative staff. With respect to gender, $38 \%$ were male and $62 \%$ were female. About $27 \%$ of the participants were single and $73 \%$ were married. As for age, $42 \%$ of the participants were under 30 years old, $40 \%$ ranged from 30 to 45 years old, and above 45 years old were $18 \%$. Concerning the educational level, holders of the secondary school certificate amounted to $35 \%$, university education $48 \%$ and Master or $\mathrm{PhD}$ degree $17 \%$. Regarding the period of experience, $32 \%$ of the participants were less than five years, $26 \%$ ranged from 5 to 10 years, and more than 10 years were $42 \%$.

\subsection{Measuring Instruments}

\subsubsection{Organizational Cynicism}

In this study, the independent variable is organizational cynicism. The researchers utilize the scale of Dean et al., (1998), Brandes, et al., (1999) and Kalağan (2009) for measuring organizational cynicism. Organizational Cynicism Scale (OCS) is comprised of the three dimensions of affect, cognition, and behavior. The affect items reflect negative emotions such as distress-anguish, anger-rage, and disgust-revulsion. Belief items reflect cognitive evaluations that employees have about the integrity and sincerity of their employing organization. Behavioral items reflect critical and disparaging behaviors associated with organizational cynicism. OCS consists of 13 statements. OCS has been measured by the five-item scale of Likert of (Completely Agree) to (Completely Disagree) where each statement has five options.

\subsubsection{Organizational Change}

The present study has investigated organizational change as a dependent variable. The researcher has drawn on the scale of Dunham, et al., (1989), Lussier (1990), and Kursunoglu \& Tanriogen (2009) for measuring organizational change. Attitudes towards changes in the model are divided into three dimensions, namely cognitive, affective and behavioral. The cognitive dimension of meaning in terms of changing views on the advantages and disadvantages, benefits, requirements, knowledge needed to manage change. The affective dimension refers to feelings associated with dissatisfaction and concern in making the changes. The behavioral dimension is the action taken or to be taken in future in the face of change or resist change. This measure consists of 18 statements. A Likert scale was used for 
judging levels of agreement or disagreement, ranging from (5) which refers to full agreement and (1) which refers to full disagreement. The informant should select the answer that suits his choice, where (5) indicates full agreement while (1) indicates full disagreement, with neutral degrees in- between.

\subsubsection{Data Analysis and Testing Hypotheses}

The researcher has employed the following methods (1) the Alpha Correlation Coefficient (ACC), (2) Multiple Discriminant Analysis (MDA), (3) Multiple Regression Analysis (MRA), and (4) the statistical testing of hypotheses which includes Wilk's Lambda, chi-square, F-test and T-test.

\section{Hypotheses Testing}

\subsection{Evaluating Reliability}

The reliability of organizational cynicism, and change were assessed to reduce errors of measuring and maximizing constancy of these scales.

Table 2. Reliability of Organizational Cynicism

\begin{tabular}{|l|l|l|}
\hline $\begin{array}{l}\text { The Dimension of } \\
\text { Organizational Cynicism }\end{array}$ & Number of Items & Alpha Value \\
\hline The Cognitive Dimension & 5 & 0.646 \\
\hline The Affective Dimension & 4 & 0.919 \\
\hline The Behavioral Dimension & 4 & 0.723 \\
\hline Total Measurement & $\mathbf{1 3}$ & $\mathbf{0 . 8 6 5}$ \\
\hline
\end{tabular}

Table (2) reveals that all the constructs, namely, cognitive, affective, and behavioral, exhibit adequate reliability with internal consistency values of $0.65,0.92$, and 0.72 respectively, which is greater than an alpha value of 0.60 (Nunnally \& Bernstein, 1994). The overall reliability of the preferred organizational questionnaire is 0.86 , proving that organizational cynicism scale is reliable.

Table 3. Reliability of Organizational Change

\begin{tabular}{|l|l|l|}
\hline $\begin{array}{l}\text { The Dimension of } \\
\text { Organizational Change }\end{array}$ & Number of Items & Alpha Value \\
\hline The Cognitive Dimension & 6 & 0.860 \\
\hline The Affective Dimension & 6 & 0.841 \\
\hline The Behavioral Dimension & 6 & 0.866 \\
\hline Total Measurement & $\mathbf{1 8}$ & $\mathbf{0 . 9 0 6}$ \\
\hline
\end{tabular}

Table (3) presents the reliability of the scales measured through Cronbach's alpha. The reliabilities of the cognitive, affective, and behavioral scales are $0.86,0.84$ and 0.86 respectively. The overall reliability of the preferred organizational questionnaire is 0.91 , proving that organizational change scale is reliable.

\subsection{Organizational Cynicism}

The evaluative attitudes of employees towards organizational cynicism are studied. The first hypothesis to be tested is:

\section{H1: There is no discrimination among the employees at Teaching Hospitals in Egypt towards organizational cynicism.}

The MDA was applied on three groups of employees regarding their evaluative attitudes towards organizational cynicism as presented in Tables (4) and (5).

Table 4. MDA of Organizational Cynicism

\begin{tabular}{|r|r|r|r|r|r|r|}
\hline Function & The \% of Differences & MCC & Wilks Lambada & Ch-Square & Degree of Sign & Level of Sign \\
\hline 1 & 66.0 & 0.217 & 0.929 & 21.657 & 6 & 0.001 \\
\hline 2 & 34.0 & 0.157 & 0.975 & 7.420 & 2 & 0.024 \\
\hline \multicolumn{7}{|c|}{ The Percentage of the exact division } \\
\hline
\end{tabular}


According to MDA, the most important findings include the following:

1. There is a high degree of difference among attitudes of employees towards organizational cynicism (the percentage of differentiation was $66 \%$ of DF).

2. There is a strong significant relationship (MCC represents 0.22 in the DF) and a statistically significant relationship at level 0.01 between teaching hospitals of the employees groups and their evaluative attitudes towards organizational cynicism.

3. The accurate classification of employees according to their evaluative attitudes towards organizational cynicism is $44 \%$. The rest, $56 \%$, are similar.

4. There are three variables relating to organizational cynicism. They have an ability to discriminate among employees (see Table 5), most importantly "my hospital's policies, goals, and practices seem to have little in common" (discrimination coefficients represent 0.92), and "when I think about my hospital, I get angry" (discrimination coefficients represent 0.77 ).

5. According to the mean of the three groups of employees (see Table 5), it was revealed that there are differences among them. As for physicians, they tend to agree, for example, that "if an application was said to be done in my hospital, I'd be more skeptical whether it would happen or not" (with a mean of 3.75), and "when I think about my hospital I get angry" (with a mean of 3.03). As for nurses, they tend to agree, for example, that "if an application was said to be done in my hospital, I'd be more skeptical whether it would happen or not" (with a mean of 3.85), and "when I think about my organization I get angry" (with a mean of 3.52). As for administrative staff, they tend to agree, for example, that "if an application was said to be done in my hospital, I'd be more skeptical whether it would happen or not" (with a mean of 3.44), and "when I think about my organization I get angry" (with a mean of 3.38).

Table 5. The Mean of Employees Towards Organizational Cynicism

\begin{tabular}{|l|l|l|l|l|}
\hline \multicolumn{1}{|c|}{ The Variables } & \multicolumn{3}{c|}{ Mean } & \multicolumn{1}{c|}{ Level } \\
of Sig
\end{tabular}

Accordingly, the null hypothesis is rejected because the value of Wilks Lambda amounts to 0.24 (see table 4). Moreover, the value of chi-square calculated (21.66) in the free degree of (6) exceeds its table counterpart (12.59) at the statistical significance level of 0.01 (see table 4). Furthermore, it was decided to reject the same null hypothesis of three variables of organizational cynicism (13 variables) at the statistical significance level of 0.01 , according to the test of univariate $F$. (see table 5).

\subsection{Organizational Change}

The evaluative attitudes of employees towards organizational change are judged. The second hypothesis to be tested is:

H2: There is no discrimination among the employees at Teaching Hospitals in Egypt regarding organizational change.

The MDA was applied on three groups of employees and their evaluative attitudes towards organizational change as displayed in Tables (6) and (7).

Table 6. MDA of Organizational Change

\begin{tabular}{|c|c|c|c|c|c|c|}
\hline Function & The \% of Differences & MCC & Wilks Lambada & Ch-Square & Degree of Sign & Level of Sign \\
\hline 1 & 79.8 & 0.275 & 0.905 & 29.34 & 8 & 0.000 \\
\hline 2 & 20.2 & 0.143 & 0.980 & 6.06 & 3 & 0.108 \\
\hline \multicolumn{7}{|c}{ The Percentage of the exact division } \\
\hline
\end{tabular}


According to MDA, the most important findings include the following:

1. There is a high degree of difference among attitudes of employees towards organizational change (the percentage of differentiation was $79 \%$ of DF).

2. There is a strong significant relationship (MCC represents 0.27 in the DF) and a statistically significant relationship at level 0.01 between teaching hospitals of the employees groups and their evaluative attitudes towards organizational change.

3. The accurate classification of employees according to their evaluative attitudes towards organizational change is $45 \%$ which is not a high percentage. Fifty five percentage of the employees are similar.

4. There are four variables relating to organizational change. They can discriminate among employees (see Table 7), most importantly " I usually hesitate to try any new ideas in this hospital (discrimination coefficients represent 0.65 ), and I usually resist new ideas in this hospital (discrimination coefficients represent 0.53 ).

5. According to the mean of the three groups of employees (see Table 7), it was revealed that there are differences among them. As for physicians, they tend to agree, for example, that "change in the hospital helps me to achieve better performance" (with a mean of 3.85) and "I usually suggest new ways to accomplish what is required of me to work in the hospital"(with a mean of 3.80). As for nurses, they tend to agree, for example, that "I usually suggest new ways to accomplish what is required of me to work in the hospital" (with a mean of 3.88) and "change in the hospital helps me to achieve better performance" (with a mean of 3.53). As for administrative staff, they tend to agree to a high degree, for example, that " change in the hospital helps me to achieve better performance" (with a mean of 3.68) and "I usually suggest new ways to accomplish what is required of me to work in the hospital"(with a mean of 3.62).

Table 7. The Mean of Employees Towards Organizational Change

\begin{tabular}{|c|c|c|c|c|}
\hline \multirow[b]{2}{*}{ The Variables } & \multicolumn{3}{|c|}{ Mean } & \multirow{2}{*}{$\begin{array}{l}\text { Level } \\
\text { Of Sig }\end{array}$} \\
\hline & $\begin{array}{c}\text { Group } \\
1\end{array}$ & $\begin{array}{c}\text { Group } \\
2\end{array}$ & $\begin{array}{c}\text { Group } \\
3\end{array}$ & \\
\hline 1. I usually hesitate to try any new ideas in this hospital. & 2.59 & 2.85 & 2.97 & 0.650 \\
\hline 2. I usually resist new ideas in this hospital. & 2.37 & 2.71 & 2.24 & $0.525^{*}$ \\
\hline $\begin{array}{l}\text { 3. Change in the hospital helps me to achieve better } \\
\text { performance. }\end{array}$ & 3.85 & 3.53 & 3.68 & $0.443^{*}$ \\
\hline $\begin{array}{l}\text { 4. I usually suggest new ways to accomplish what is } \\
\text { required of me to work in the hospital. }\end{array}$ & 3.80 & 3.88 & 3.62 & 0.339 \\
\hline
\end{tabular}

Accordingly, the null hypothesis is rejected because of the value of Wilks Lambda amount to 0.27 (see table 6). Besides the value of chi-square calculated (29.34) in the free degree of (8) exceeds its table counterpart (15.51) at the statistical significance level of 0.01 (see table 6). Furthermore, it was decided to reject the same null hypothesis of four variables of organizational change (18 variables) at the statistical significance level of 0.01, according to the test of univariate $F$ (see table 7).

\subsection{Organizational Cynicism and Change}

The relationship between organizational cynicism and change are investigated. The third hypothesis to be tested is:

H3: There is no relationship between organizational cynicism and organizational change at Teaching Hospitals in Egypt.

Table 8. Correlation Between Organizational Cynicism and Change

\begin{tabular}{|c|c|c|c|c|}
\hline Hypothesis & Independent Variables & Dependent Variables & Pearson Correlation & Sig \\
\hline \multirow{3}{*}{$H 3$} & Cognitive Dimension & \multirow{3}{*}{ Organizational Change } & $0.303^{* *}$ & 0.00 \\
\cline { 4 - 5 } & Affective Dimension & $0.433^{* *}$ & 0.00 \\
\cline { 4 - 5 } & Behavioral Dimension & & $0.435^{* *}$ & 0.00 \\
\cline { 3 - 4 } & & $\mathbf{0 . 4 8 1} 1^{* *}$ & $\mathbf{0 . 0 0}$ \\
\hline \multicolumn{2}{|l|}{ Total Measurement } \\
\cline { 3 - 4 } Note: ** Correlation is significant at 0.01 level.
\end{tabular}

Table (8) reveals the significant correlation between organizational cynicism and change. 
Table 9. The Relationship Between Organizational Cynicism and Change

\begin{tabular}{|l|l|l|l|}
\hline The Variables of Organizational Cynicism & Beta & $\mathbf{R}$ & $\mathbf{R}^{\mathbf{2}}$ \\
\hline The Cognitive Dimension & $0.124^{*}$ & $0.303^{* *}$ & 0.092 \\
\hline The Affective Dimension & $0.208^{* *}$ & $0.433^{* *}$ & 0.187 \\
\hline The Behavioral Dimension & $0.250^{* *}$ & $0.435^{* *}$ & 0.189 \\
\hline - $\quad$ Multiple Correlation Coefficients (MCC) & 0.486 & \\
- $\quad$ Determination Coefficient (DC) & 0.236 & \\
- $\quad$ The Value of Calculated F & 30.549 & \\
- $\quad$ Degree of Freedom & 3,296 & \\
- The Value of Indexed F & 3.78 & \\
- $\quad$ Level of Significant & 0.000 & \\
\hline$* \mathrm{P}<.05 * * \mathrm{P}<.01$ & & \\
\hline
\end{tabular}

Table (9) presents the type and strength of the relationship between organizational cynicism and change using MRA. Findings include the following:

1. According to MCC, there is a statistically significant relationship between organizational cynicism and organizational change, $49 \%$.

2. Based on DC, organizational cynicism may interpret $24 \%$ of the total differentiation in organizational change.

3. On the basis of MRA, the variables of organizational cynicism providing more explanation of the difference in the level of organizational change include the behavioral dimension $(0.25)$, the affective dimension $(0.21)$ and finally the cognitive dimension (0.13).

As a result, the null hypothesis is rejected and the alternative hypothesis is accepted. This is because the model of MRA has shown that there was fundamental relationship between organizational cynicism and organizational change at the statistical significance level of 0.01, according to T-Test (See Table 9).

\section{Study Results}

1. The researcher was able to determine that differences exist among the employees regarding their evaluative attitudes organizational cynicism, most importantly "my hospital's policies, goals, and practices seem to have little in common", "when I think about my hospital, I get angry" and "if an application was said to be done in my hospital, I'd be more skeptical whether it would happen or not".

2. There are differences among the three groups of employees. As for physicians, they tend to agree that "if an application was said to be done in my hospital, I'd be more skeptical whether it would happen or not", and "when I think about my hospital I get angry". As for nurses, they tend to agree that "if an application was said to be done in my hospital, I'd be more skeptical whether it would happen or not", and "when I think about my organization I get angry". As for administrative staff, they tend to agree that "if an application was said to be done in my hospital, I'd be more skeptical whether it would happen or not", and "when I think about my organization I get angry".

3. The researcher was able to determine that differences exist among the employees regarding their evaluative attitudes organizational change, most importantly "I usually hesitate to try any new ideas in this hospital", "I usually resist new ideas in this hospital", "change in the hospital helps me to achieve better performance", and "I usually suggest new ways to accomplish what is required of me to work in the hospital".

4. There are differences among the three groups of employees. As for physicians, they tend to agree that "change in the hospital helps me to achieve better performance", and "I usually suggest new ways to accomplish what is required of me to work in the hospital". As for nurses, they tend to agree that "I usually suggest new ways to accomplish what is required of me to work in the hospital", and "change in the hospital helps me to achieve better performance". As for administrative staff, they tend to agree to a high degree that " change in the hospital helps me to achieve better performance", and "I usually suggest new ways to accomplish what is required of me to work in the hospital". 
5. There is a statistically significant relationship between the dimensions of organizational cynicism (the cognitive dimension, the affective dimension and the behavioral dimension ) and organizational change at Teaching Hospitals in Egypt.

\section{Recommendations}

\subsection{Recommendations relating to Organizational Cynicism}

1. Managers in organizations need to play a more active and vital role in preventing cynicism. Administrators must adopt an open-door policy. This will provide employees the opportunity to freely express their views to managers and administrators without being reprimanded.

2. By learning more about the causes of cynicism, managers can address certain issues that have a tendency to trigger such unwanted behaviors. Having weekly conversations with each employee (i.e., one-on-one) can be a great time and venue for such conversations to take place.

3. Managers need to be more understanding when dealing with all employees. Thus, emotional intelligence training for all managers can be effective. "For success in the modern workforce, which is mostly practiced in an increasingly stressful and emotionally taxing environment characterized by high competition, constant transformation and looming uncertainty, emotional intelligence skills provide an advantage" (Kaifi \& Noori, 2010).

4. Management can influence the level of cynicism by ensuring that all successful changes are clearly publicized. No matter how small the change is, if it is in the direction intended by management, it should be communicated.

5. Organizations must learn to manage values with care to avoid disillusionment and organizational cynicism among employees and recruit people who have lower general cynicism.

6. There are indications of unethical tendencies being less among managers in middle and senior management positions. The role of organizational culture in improving ethicality warrants added attention. Future work might incorporate other research methodologies in measuring organizational cynicism and ethical behavior to further our understanding of this causation.

\subsection{Recommendations relating to Organizational Change}

1. Propagating the culture of change among employees at all levels through workshops, symposia and meetings. This will attain important developments at Teaching Hospitals in Egypt.

2. Defining priorities of Teaching Hospitals in respect to change at all administrative levels, as well as providing all information relating to change. This will turn the administrative process more flexible, clear out all ambiguity and avoid all resistance expected from some employees.

3. Preparing a plan for change at Teaching Hospitals, in which all administrative levels should take part. The other employees should be qualified so that all workers at hospitals may feel that the plan is theirs. This will help the higher administration in carrying out procedural activities, especially in regard to change.

4. Making use of the experienced employees for the success of the organizational change and assisting the higher administration in specifying the goals that suit the organizational change besides evaluating effectiveness of the means and measures adopted to attain the goals of organizational change.

5. Increasing the number of training courses for all employees, taking into account the current and future goals and plans. These courses raise awareness, sharpen potentials, develop skills and enrich experience. This gets positively reflected on effectiveness of work.

6. A thorough plan must be outlined to apply organizational change, including suitable time to carry out necessary studies.

7. Managers and employees at all levels of administration should take part in any change intended by the organization. This will help create positive stands towards organizational change. These attitudes turn into tangible reality improving performance and its effectiveness.

8. Culture of organization must be provided regarding reinforcing and boosting organizational change. This is to be attained via preparation of the internal circumstances stressing the import of renewal and creativity, as well as monitoring points of weakness and strength in organizational change.

\section{Limitations and Future Research}

Several limitations of this study should be considered. First, the research population is Teaching Hospitals in Egypt. This sector includes nine Hospitals. The researcher excludes Hospitals in Sohag and Aswan. This explains why the 
population of this study involves all employees (physicians, nurses, and administrative staff). Also, the present study has drawn on the questionnaire method for collecting primary data necessary for the study. The questionnaire list is interested in recognizing organizational cynicism and change.

There are several areas for possible future research. First, it will be useful to investigate the relationship between organizational cynicism and change at larger organizations. Second, a comparative analysis between private and public hospitals may be made. This subject may be applied in different fields other than the health sector. Future researches also need to investigate the relationship between organizational cynicism and burnout of employees. Finally, future studies need to examine the relationship between organizational cynicism and organizational commitment.

\section{Conclusion and Implications}

For individual managers, the practical implications begin with the recognition that employee cynicism is an important attitude with significant consequences. Within the scope of the study, the concept of organizational cynicism is generated by trying to point out the levels of organizational cynicism among the Teaching Hospitals in Egypt. It has been concluded that there are differences among the employees regarding their evaluative attitudes towards organizational cynicism and organizational change. However the cognitive, affective, and behavioral dimensions of organizational cynicism have a significant relationship with organizational change.

Since organizational cynicism is associated with many other concepts such as job satisfaction and organizational commitment, managers should deepen the perception of organizational justice that can be realized without spending much effort and resources. In organizations with a high sense of justice, motivation and internal loyalty, employees are more likely to be more loyal to their work and organizations.

Organizational training should become the norm in many organizations where managers discuss specific attitudes that affect the organization's culture while emphasizing both the short-term and long-term implications of organizational cynicism. In order for an organization to be competitive, it becomes imperative for its human resources to focus on creativity, innovativeness, unity, and efficacy. Thus, distractions of organizational cynicism can be disastrous for an organization should be reprimanded.

Quarterly surveys should also be used to gauge how employees are feeling so managers can create a healthier environment for all employees. Needless to say, stress can be the root cause of organizational cynicism and stress can come in many different forms and from many different internal and external factors. Future researchers should consider investigating the relationship between stress and organizational cynicism.

Management can influence the level of cynicism by addressing its two components, pessimism and dispositional attributions. Regarding pessimism, one strategy is to make sure that all successful changes are clearly publicized.

Managing the attributions made about the lack of change is the second way to manage levels of cynicism. The key here is again information so that employees will make situational rather than dispositional attributions.

There are some actions that can be taken. First, the more employees are involved directly in the change process itself, the less they will make dispositional attributions because there is no blame. Second, the less employees are surprised by management actions and the more they understand the reasons for the actions, the more they will see things from the management perspective. This will reduce the tendency to make dispositional attributions like blaming selfish or incompetent management. Third, past failures need to be fully explained rather than ignored. It may be true that the past cannot be undone, but it can have a strong influence on the present and future through the attributions made by employees. If past failure is attributable to management mistakes, they should be acknowledged to preserve credibility.

Finally, it is important that management make serious efforts to see the situation from the lower level employees' perspective to understand why they tend to blame management.

\section{References}

Abraham, R. (2000). Organizational Cynicism: Bases and Consequences. Genetic, Social, and General Psychology Monographs, Vol. 126, No. 3, PP.269- 292.

Achor, S. (2012). Positive Intelligence. Harvard Business Review, January-February 2012, 100-102.

Andersson, L. (1996). Employee Cynicism: An Examination Using a Contract Violation Framework. Human Relations, PP. 1397-1398. http://dx.doi.org/10.1177/001872679604901102

Barefoot, J., Dodge, K.., Peterson, B., Dahlstrom, W., \& Williams, R. (1989). The Cook-Medley Hostility Scale. Item 
Content and Ability to Predict Survival, Psychosomatic Medicine, No.51, PP. 46-57.

Brandes, P., Dharwadkar, R. \& Dean, J. (1999). Does Employee Cynicism Matter? Employee and Supervisor Perspectives on Work Outcomes. Paper Presented at the Eastern Academy of Management, Philadelphia.

Cao, G., Clarke, S., Lehaney, B. (2000). A systematic View of Organizational Change and TQM, The TQM Magazine, Vol. 12 No.3, PP.186-193.

Cole, M., Brunch, H., \& Vogel, B. (2006). Emotion as Mediators of the Relations between Percived Supervision Support and Psychological Hardiness on Employee Cynicism, Journal of Organizational Behavior, Vol. 27, PP. 463-484.

Daniel W. (1999). Biostatistics: A Foundation For Analysis in the Health Sciences. $7^{\text {th }}$ edition. New York, John Wiley \& Sons.

Dean J., Brandes, P., \& Dharwadkar, R. (1998). Organizational Cynicism. The Academy of Management Review, Vol. 23, No. 2, PP. 341-352.

Dunham, R., Grube, J., Gardner, D., Cummings, L., Pierce, J. (1989). The Development of An Attitude Toward Change Instrument, Paper Presented at the Academy of Management Annual Meeting, Washington, DC.

Elizur, D., Guttman, L. (1976). The Structure of Attitudes Toward Work and Technological Change within an Organization, Administrative Science Quarterly, Vol. 21 PP..611-23.

Ince, M., \& Turan, S., (2011). Organizational Cynicism as A Factor that Affects the Organizational Change in the Process of Globalization and An Application in Karaman's Public Institutions, Journal of Economics, Finance and Administrative Sciences, Issue 37, PP.104-121.

Kaifi, B., (2013). Organizational Behavior: Managing and Leading Organizations. Tamarac, FL: Llumina Press.

Kaifi, B.A. (2010). Managing Your Future: An Educational Guide. Davie, Florida. ILEAD Academy.

Kalağan, G. (2009). Araştırma Görevlilerinin Örgütsel Destek Algıları İle Örgütsel Sinizm Tutumları Arasındaki İlişki, Yayınlanmamış Yüksek Lisans Tezi, Akdeniz Üniversitesi Sosyal Bilimler Enstitüsü.

Khademian, A. (2002). Working With Culture. Washington, D.C.: CQ Press.

Koretz, G. (2003). Hate Your Job? Join the Club. Business Week.

Kouzes, J. (2003). Encouraging the Heart: A Leader's Guide to Rewarding and Recognizing Others, San Francisco, CA: Jossey-Bass.

Kouzes, J. M., \& Posner, B. Z. (2003). The Leadership Practices Inventory: Facilitator's Guide, (3 ${ }^{\text {rd }}$ ed.), San Francisco, John Wiley and Sons.

Lawrence-Lightfoot, S. (2000). Respect. Cambridge, MA: Perseus Books.

Nunnally J., \& Bernstein I., (1994), Psychometric Theory, McGraw-Hill, New York.

Özgener, Ş., Öğüt, A., Kaplan, M., (2008). İşgören-İşveren İlişkilerinde Yeni Bir Paradigma: Örgütsel Sinizm, İçinde Özdevecioğlu, M. Karadal, (Ed.) Örgütsel Davranışta Seçme Konular: Organizasyonların Karanlık Yönleri ve Verimlilik Azaltıcı Davranışlar, Ankara: İlke Yayınevi, PP. 53-72.

Özler E., Derya, A., Giderler C., Şahin D. (2010). Örgütlerde Sinizm Güvensizlikle Mi Bulaşır?, Organizasyon ve Yönetim Bilimleri Dergisi, Vol. 2, No. 2, PP. 47-57.

Pettigrew, A.M., Woodman, R.W. \& Cameron, K.S. (2001). "Studying organizational change and development: challenges for future research", Academy of Management Journal, Vol. 44 No. 4, pp. 697-713. http://dx.doi.org/10.2307/3069411

Rainey, H.G. (2003). Understanding and Managing Organizations (3rd ed). San Francisco, CA: Jossey-Bass.

Reichers, A., Wanous, J., \& Austin, J., (1997). Understanding and Managing Cynicism About Organizational Change. Academy of Management Executive, Vol. 11, No.1, PP. 48-59.

Rubin R. S., Dierdorff E. C., Bommer W. H., \& Baldwin T. T. (2009). Do Leaders Reap What They Sow? Leader and Employee Outcomes of Leader Organizational Cynicism about Change. The Leadership Quarterly, 20, s. 680. http://dx.doi.org/10.1016/j.leaqua.2009.06.002

Stanley, D. Meyer, J. \& Topolnytsky, L (2005). Employee Cynicism and Resistance to Organizational Change. Journal of Business and Psychology, 19, No. 4, PP. 429-459. http://dx.doi.org/10.1007/s10869-005-4518-2

Wanous, J.P, Reichers, A.E, \& Austin, J.T. (2000). Cynicism About Organizational Change: Measurement, Antecedent and correlates, Group and Organizational Management, 25(2), 132- 153. http://dx.doi.org/10.1177/1059601100252003 